\title{
Sistem Pendukung Keputusan Team Survei Terbaik Pada SNI (Serikat Nelayan Indonesia) Menggunakan Metode SMART (Studi Kasus: Sekretariat SNI, Medan)
}

\author{
Muhammad Yusuf*, Nelly Astuti Hasibuan \\ Program Studi Teknik Informatika Universitas Budi Darma, Medan, Indonesia \\ Email: ${ }^{1}$ muhyusuf@gmail.com \\ Submitted: 04/09/2020; Accepted: 22/01/2021; Published: 30/05/2021
}

\begin{abstract}
Abstrak-Survei biasanya dirancukan dengan istilah observasi dalam pengertian sehari - hari, survei juga merupakan suatu cara yang utama untuk mengumpulkan data primer bila data skunder dianggap belum cukup lengkap untuk menjawab sesuatu pertanyaan, kalau data skunder sudah cukup lengkap dan hipotesis sudah dapat diuji dengan data skunder maka pengumpulan data primer secara langsung dengan metode survei tidak perlu lagi, survei adalah mencari informasi faktual secara mendetail yang sedang menggejala dan mengindentifikasikan masalah-masalah atau untuk mendapat justifikasi keadaan dan kegiatankegiatan yang sedang berjalan untuk mengetahui hal-hal yang dilakukan oleh orang-orang yang menjadi sasaran penelitian dalam memecahkan masalah, sebagai bahan penyusunan rencana dan pengambilan keputusan dimasa mendatang. SMART (Simple Multi - Attribute Rating Technique ) merupakan metode pengambilan keputusan multi kriteria yang dikembangkan oleh Edward pada tahun 1977. Teknik pengambilan keputusan multi kriteria ini didasarkan pada teori bahwa setiap alternatif terdiri dari sejumlah kriteria yang memiliki nilai - nilai dan setiap kriteria memiliki bobot yang menggambarkan seberapa penting ia dibandingkan dengan kriteria lain. Pembobotan ini digunakan untuk menilai setiap alternatif agar diperoleh alternatif terbaik. SMART menggunakan linear additive model untuk meramal nilai setiap alternatif. SMART merupakan metode pengambilan keputusan yang fleksibel.
\end{abstract}

Kata Kunci: Team; Survei; SNI; Metode SMART

Abstract-Surveys are usually confused with the term observation in the everyday sense, surveys are also the main way to collect primary data if secondary data are deemed incomplete to answer a question, if the secondary data is complete enough and the hypothesis can be tested with secondary data then Direct primary data collection using the survey method is no longer necessary, a survey is looking for detailed factual information that is currently symptomatic and identifying problems or to justify conditions and ongoing activities to find out what people are doing which is the target of research in solving problems, as material for planning and making decisions in the future. SMART (Simple Multi - Attribute Rating Technique) is a multicriteria decision-making method developed by Edward in 1977.This multi-criteria decision-making technique is based on the theory that each alternative consists of a number of criteria that have values and each criterion has a weight describes how important it is compared to other criteria. This weighting is used to assess each alternative in order to obtain the best alternative. SMART uses a linear additive model to predict the value of each alternative. SMART is a flexible decision making method.

Keywords: Team; Survey; SNI; SMART Method

\section{PENDAHULUAN}

Organisasi merupakan sekumpulan orang atau kelompok untuk mencapai suatu tujuan dengan cara dan aturan tertentu secara umum tujuan dari organisasi adalah untuk mencapai tujuan individu yang dilaksanakan secara kelompok. Jenis dari pada organisasi sangat beragam, seperti : organisasi masa, organisasi keluarga, organisasi masyarakat, organisasi sekolah, organisasi politik, dan organisasi internasional, setiap jenis organisasi ini mempunyai tujuan dan mekanisme yang berbeda - beda.

SNI (Serikat Nelayan Indonesia) sebagai organisasi masa nelayan tradisional untuk memperjuangkan hak - hak ekonomi, sosial, politik, dan budaya tradisional demi mewujudkan kesejahteraan bersama melalui pengelolaan sumberdaya laut dan tata perekonomian yang adil, disetiap organisasi mempunyai team yaitu team survei, yang mana team tersebut dapat bekerja dengan baik dan profesianal atas tugas yang diberikan.

Survei sering disebut penelitian kuantitatif dengan menggunakan pertanyaan terstruktur yang sama pada setiap orang, kemudian semua jawaban yang diperoleh peneliti dicatat, diolah, dan dianalisis. Survei juga merupakan metode menjaring data penduduk dalam beberapa peristiwa demografi atau ekonomi di daerah pesisir dengan tidak menghitung seluruh responden yang ada di suatu daerah dan team survei yang dilakukan oleh SNI (Serikat Nelayan Indoneia) turun langsung kedaerah - daerah maupun desa - desa dengan cara kuesioner (wawancara) terhadap masyarakat khususnya masyarakat yang tinggal dipesisir, SNI (Serikat Nelayan Indonesia) mempunyai 7 team survei yang mana team survei tersebut mempunyai team survei terbaik yang dilihat dari pertanyaan yang dilontarkan kepada masyarakat pesisir dan pemilihan team surveipun dipilih secara aklamasi, pemilihan tersebut dilakukan dimana program bantuan dari pemerintah untuk masyarakat disitulah pemilihan atau penentuan team survei yang akan menyurvei.

Team survei juga mempunyai kendala atau masalah yang mana dari segi faktor internal maupun faktor eksternal. Faktor internal yang mana kurangnya pengetahuan akan survei, ketidak mampuan melakukan strategi secara efektif, biaya oprasional surveyor, tidak adanya percaya diri dalam satu team. Sedangkan faktor eksternal adalah pengaruh dari team survei lain, dan kurangnya pengetahuan tentang perubahan situasional disekitar lingkup kerja team survei masalah yang paling mendukung adalah pemilihan team survei, dipilih secara aklamsi dan 
penentuan team survei terbaikpun belum objektif tempat yang akan disurveipun dipilih secara multistage random sampling (acak) dari beberapa daerah.

Sistem Pendukung Keputusan merupakan pengambilan keputusan terbaik untuk meningkatkan kemampuan para pengambil keputusan dengan memberikan alternatif-alternatif keputusan yang lebih banyak atau lebih baik, sistem pendukung keputusan juga bagian dari sistem informasi berbasis komputer termasuk sistem berbasis pengetahuan atau manajemen pengetahuan yang dipakai untuk mendukung pengambilan keputusan dalam suatu organisasi atau perusahaan[1]-[3].

Dengan menggunakan metode SMART sistem pendukung keputusan ini dapat membantu Serikat Nelayan Indonesia (SNI) dalam menggambil keputusan yang lebih tepat dalam menentukan team survey terbaik dan juga desa-desa atau masyarakat-masyarakat yang memerlukan dampingan atau arahan-arahan dalam melestarikan sumberdaya laut.

\section{METODE PENELITIAN}

\subsection{Sistem Pendukung Keputusan}

Sistem pendukung keputusan adalah pemilihan diantara alternatif-alternatif untuk mengukur alternatif-alternatif tersebut meggunakan data statistik, data statistik dapat dikumpulkan dengan menggunakan prosedur yang sistematis[4], [5].

\subsection{Metode SMART}

SMART merupakan metode pengambilan keputusan yang multiatribut. Teknik pembuatan keputusan multiatribut ini digunakan untuk membantu stakeholder dalam memilih antara beberapa alternatif. Setiap alternarif terdiri dari sekumpulan atribut dan setiap atribut mempunyai nilai-nilai, nilai ini dirata-rata dengan skala tertentu. Setiap atribut mempunyai bobot yang menggambarkan seberapa penting ia dibandingkan dengan atribut lain[6]-[8]. Dengan SMART pembobotan atribut dilakukan dengan dua langkah yaitu:

a) Mengurutkan kepentingan suatu atribut dari level terburuk ke level terbaik.

b) Membuat perbandingann rasio kepentingan setiap atribut dengan atribut lain dibawahnya.

SMART lebih banyak digunakan karena kesederhanaanya dalam merespon kebutuhan pembuat keputusan dan caranya menganalisa respon. Analisa yang terlibat adalah transparan sehingga metode ini memberikan pemahaman masalah yang tinggi dan dapat diterima oleh pembuat keputusan. Pembobotan pada SMART menggunakan skala antara 0 sampai 1, sehingga mempermudah perhitungan dan perbandingan nilai pada masingmasing alternatif.

Model yang digunakan dalam SMART (Simple Multi Attribute Rating Technique) yaitu :

$$
\mathrm{u}\left(\mathrm{a}_{i}\right)=\sum_{j=1}^{m} w_{j} u_{i}\left(a_{i}\right), \quad \mathrm{i}=1,2, \ldots \mathrm{m}
$$

Keterangan

$\mathrm{w}_{\mathrm{j}} \quad=$ nilai pembobotan kriteria ke-j dan $\mathrm{k}$ kriteria

$\mathrm{u}\left(\mathrm{a}_{\mathrm{i}}\right) \quad$ = nilai utility kriteria ke-i untuk kriteria ke-i

Pemilihan keputusan adalah mengidentifikasi mana dari $\mathrm{n}$ alternatif yang mempunyai nilai fungsi terbesar.

Teknik Motode SMART :

Langkah $1:$ menentukan jumlah kriteria

Langkah 2 : sistem secara default memberikan skala 0-100 berdasarkan prioritas yang telah diinputkan kemudian dilakukan normalisasi.

$$
\text { Normalisasi }=\frac{w_{j}}{\sum w_{j}}
$$

Keterangan $: w_{j} \quad$ : bobot suatu kriteria

Langkah 3 : memberikan nilai kriteria untuk setiap alternatif.

Langkah 4 : hitung nilai utility untuk setiap kriteria masing-masing.

Keterangan :

$$
\mathrm{u}_{\mathrm{i}}\left(\mathrm{a}_{\mathrm{i}}\right)=100 \frac{\left(C_{\max }-C_{\text {outi }}\right)}{\left(C_{\max }-C_{\min }\right)} \%
$$

$\mathrm{u}_{\mathrm{i}}\left(\mathrm{a}_{\mathrm{i}}\right)$ : nilai utility kriteria ke-1 untuk kriteria ke-i

$\mathrm{C}_{\max }$ : nilai kriteria maksimal

$\mathrm{C}_{\min }$ : nilai kriteria minimal

$\mathrm{C}_{\text {out i }}$ : nilai kriteria ke-i

Langkah 5 : hitung nilai akhir masing-masing.

$$
u_{i}\left(a_{i}\right)=\sum_{j=1}^{m} w_{j} u_{i}\left(a_{i}\right)
$$

\subsection{Team Survei}

Survei biasanya dirancukan dengan istilah observasi dalam pengertian sehari - hari, survei juga merupakan suatu cara yang utama untuk mengumpulkan data primer bila data skunder dianggap belum cukup lengkap untuk menjawab sesuatu pertanyaan, kalau data skunder sudah cukup lengkap dan hipotesis sudah dapat diuji dengan 
data skunder maka pengumpulan data primer secara langsung dengan metode survei tidak perlu lagi, survei adalah mencari informasi faktual secara mendetail yang sedang menggejala dan mengindentifikasikan masalah-masalah atau untuk mendapat justifikasi keadaan dan kegiatan-kegiatan yang sedang berjalan untuk mengetahui hal-hal yang dilakukan oleh orang-orang yang menjadi sasaran penelitian dalam memecahkan masalah, sebagai bahan penyusunan rencana dan pengambilan keputusan dimasa mendatang.

\section{HASIL DAN PEMBAHASAN}

Setelah menentukan bidang penelitian yang dikaji dan melakukan pengumpulan data terkait dengan Pengambilan Keputusan Team Survei Terbaik dengan menggunakan metode SMART maka tahap selanjutnya adalah menganalisa sistem. SNI (Serikat Nelayan Indonesia) Medan pemilihan Team Surveinya masih dilakukan dengan subjektif dan untuk mengatasi permasalahan tersebut,karena dalam sistem pendukung keputusan memiliki proses perhitungan penilaian kriteria menggunakan metode SMART yang dapat bekerja pada situasi yang kompleks dan memungkinkan untuk melakukan suatu analisa dengan data yang minimum, sehingga dalam melakukan proses pemilihan menjadi lebih efisien dan efektif tentunya menghasilkan keputusan yang lebih cepat tepat dan subjektif untuk menghasilkan keputusan, sistem ini membutuhkan data yang dapat mendukung pengambilan keputusan. Data yang terdapat dalam sistem ini adalah data eksternal yaitu data yang dibutuhkan yang berada di luar sistem.

\subsection{Penerapan Metode SMART}

Dalam memilih Team survei, terdapat kriteria yang bisa menjadi acuan sebagai pertimbangan penyeleksian, kriteria tersebut terdapat pada data team survei. Ada pun Data team survei adalah:

Tabel 1. Team Survei

\begin{tabular}{|c|c|c|}
\hline No & Nama Team Survei & Kriteria Team Survei \\
\hline 1 & Team Survei Kesehatan & $\begin{array}{l}\text { Manajemen strategis, Pengumpulan data kuisioner, } \\
\text { Observasi sampel, Tata bahasa }\end{array}$ \\
\hline 2 & Team Survei Pendidikan & $\begin{array}{l}\text { Manajemen strategis, Pengumpulan data kuisioner, } \\
\text { Observasi sampel, Tata bahasa }\end{array}$ \\
\hline 3 & Team Survei Ekonomi & $\begin{array}{l}\text { Manajemen strategis, Pengumpulan data kuisioner, } \\
\text { Observasi sampel, Tata bahasa }\end{array}$ \\
\hline 4 & $\begin{array}{l}\text { Team Survei Hubungan } \\
\text { Masyarakat }\end{array}$ & $\begin{array}{l}\text { Manajemen strategis, Pengumpulan data kuisioner, } \\
\text { Observasi sampel, Tata bahasa }\end{array}$ \\
\hline 5 & Team Survei Lingkungan & $\begin{array}{l}\text { Manajemen strategis, Pengumpulan data kuisioner, } \\
\text { Observasi sampel, Tata bahasa }\end{array}$ \\
\hline 6 & $\begin{array}{l}\text { Team Survei Pemberdayaan } \\
\text { Wanita }\end{array}$ & $\begin{array}{l}\text { Manajemen strategis, Pengumpulan data kuisioner, } \\
\text { Observasi sampel, Tata bahasa }\end{array}$ \\
\hline 7 & Team Survei Pembudidayaan & $\begin{array}{l}\text { Manajemen strategis, Pengumpulan data kuisioner, } \\
\text { Observasi sampel, Tata bahasa }\end{array}$ \\
\hline
\end{tabular}

Dalam pemilihan Team Survei, terdapat kriteria yang bisa menjadi acuan sebagai pertimbangan penyeleksian, yaitu Manajemen strategis, Pengumpulan data kuisioner, Observasi sampel, Tata bahasa SNI (Serikat Nelayan Indonesia) Medan, akan melakukan pemilihan Team survei terbaik, dari program-program yang telah disajikan oleh SNI (Serikat Nelayan Indonesia) Medan

Langkah - langkah yang dilakukan dengan metode SMART yaitu :

1. Menentukan jumlah kriteria

Tabel 2. Kriteria

\begin{tabular}{ll}
\hline \multicolumn{1}{c}{ Kriteria } & \multicolumn{1}{c}{ Keterangan } \\
\hline Manajemen Strategi (C1) & $\begin{array}{l}\text { Rangkaian proses atau rencana dalam mencapai } \\
\text { sasaran dan tujuan } \\
\text { Pengumpulan Data Kuisioner (C2) }\end{array}$ \\
& $\begin{array}{l}\text { Menyerahkan atau mengirimkan daftar pertanyaan } \\
\text { untuk diisi oleh responden }\end{array}$ \\
Observasi Sampel (C3) & Menganalisis dan mengadakan pencatatan secara \\
& sistematis terhadap jumlah penduduk \\
Tata Bahasa (C4) & Disiplin dalam berbahasa dan mengerti kaidah - \\
& kaidah dalam melontarkan kata - kata \\
\hline
\end{tabular}

2. Memberikan Bobot kriteria

Pada tahap ini nilai yang telah diperoleh akan dimasukkan pada rumus pembobotan.

a. Manajemen strategis : nilai yang didapat atau diperoleh sebesar 20

b. Pengumpulan data kuisioner : nilai yang didapat atau diperoleh sebesar 20

c. Observasi sampel : nilai yang didapat atau diperoleh sebesar 40 
d. Tata bahasa : nilai yang didapat atau diperoleh sebesar 20

Pembobotan dari setiap kriteria tersebut akan dibagi dengan total pembobotan setiap kriteria yang total jumlahnya 100.

Tabel 3. Bobot Penilaian

\begin{tabular}{clc}
\hline No & \multicolumn{1}{c}{ Kriteria } & Bobot \\
\hline 1. & Manajemen Strategis & 20 \\
2. & Pengumpulan Data Kuisioner & 20 \\
3. & Observasi Sampel & 40 \\
4. & Tata Bahasa & 20 \\
& Jumlah & 100 \\
\hline
\end{tabular}

Selanjutnya akan dibuat tabel pembobotan normalisasi karna setiap bobot kriteria akan dibagi dengan total bobot semua kriteria

Tabel 4. Bobot Normalisasi

\begin{tabular}{clcc}
\hline No & \multicolumn{1}{c}{ Kriteria } & Bobot & Normalisasi \\
\hline 1. & Manajemen strategis & $20 / 100$ & 0,2 \\
2. & Pengambilan data kuisioner & $20 / 100$ & 0,2 \\
3. & Observasi Sampel & $40 / 100$ & 0,4 \\
4. & Tata bahasa & $20 / 100$ & 0,2 \\
\hline
\end{tabular}

3. Memberikan penilaian pada setiap bobot alternative dan perangkingan

Berdasarkan survei yang dilakukan oleh team survei SNI (Serikat Nelayan Indonesia) dari hasil pertanyaan secara kuisioner pada masyarakat pesisir maka dapat ditentukan penilaian pada setiap bobot alternative dan penilaian range kriteria seperti, kriteria manajemen strategis, pengumpulan data kuisioner, observasi sampel, dan tata bahasa. Pemberian bobot berdasarkan kriteria paling penting dan paling tidak penting kriteria paling penting disetkan dengan bobot $60-100$ dan kriteria paling tidak penting diset dengan bobot $50-80$.

Keterangan :

Range Kriteria Penilaian Manajemen Strategis

$\begin{array}{ll}81-100 & \text { : Sangat Baik } \\ 71-80 & \text { : Baik } \\ 61-79 & \text { : Cukup } \\ <60 & \text { : Kurang }\end{array}$

Range Kriteria Penilaian Pengumpulan Data Kuisioner

$71-80 \quad$ : Sangat Baik

$61-70 \quad:$ Baik

$51-60 \quad:$ Cukup

$<50 \quad$ : Kurang

Range Kriteria Penilaian Observasi Sampel

$81-100 \quad$ : Sangat Baik

$71-80 \quad:$ Baik

$61-70 \quad$ : Cukup

$<60 \quad$ : Kurang

Range Kriteria Penelitian Tata Bahasa

$71-80 \quad$ : Sangat Baik

$61-70 \quad$ : Baik

51-60 : Cukup

$<50 \quad$ : Kurang

Tabel 5. Evaluasi Faktor

\begin{tabular}{|c|c|c|c|c|}
\hline \multirow[b]{2}{*}{ Nama Team Survei } & \multicolumn{4}{|c|}{ Faktor } \\
\hline & $\begin{array}{c}\text { Manajemen } \\
\text { Strategis / } \\
\text { Range }\end{array}$ & $\begin{array}{c}\text { Pengumpulan } \\
\text { Data Kuisioner / } \\
\text { Range }\end{array}$ & $\begin{array}{c}\text { Observasi } \\
\text { Sampel / Range }\end{array}$ & $\begin{array}{c}\text { Tata Bahasa / } \\
\text { Range }\end{array}$ \\
\hline Team Survei Kesehatan & 75 / Baik & 70 / Baik & 80 / Baik & $\begin{array}{l}75 \text { / Sangat } \\
\text { Baik }\end{array}$ \\
\hline Team Survei Pendidikan & 70 / cukup & 75 / Sangat Baik & 86 / Sangat Baik & $\begin{array}{l}75 \text { / Sangat } \\
\text { Baik }\end{array}$ \\
\hline Team Survei Ekonomi & 80 / Baik & 75 / Sangat Baik & 80 / Baik & 70 / Baik \\
\hline $\begin{array}{l}\text { Team Survei Hubungan } \\
\text { Masyarakat }\end{array}$ & 75 / Baik & 70 / Baik & 75 / Baik & 70 / Baik \\
\hline Team Survei Lingkungan & 70 / Cukup & 80 / Sangat Baik & 70 / Cukup & 70 / Baik \\
\hline
\end{tabular}




\begin{tabular}{lcccc}
\hline Team Survei Pemberdayaan & 86/ Sangat & $70 /$ Baik & $75 /$ Baik & 75 / Sangat \\
Wanita & Baik & Baik \\
Team Survei Pembudidayaan & $70 /$ Cukup & $80 /$ Sangat Baik & $86 /$ Sangat Baik & $70 /$ Baik \\
\hline
\end{tabular}

4. Menghitung nilai utility untuk setiap kriteria masing-masing Manajemen Strategis

$$
\begin{aligned}
\mathrm{C} 1 & =100 \frac{(86-75)}{(86-70)} \% \\
& =100(0,68) \%=68 \\
\mathrm{C} 2 & =100 \frac{(86-70)}{(86-70)} \% \\
& =100(1) \%=100 \\
\mathrm{C} 3 \quad & =100 \frac{(86-80)}{(86-70)} \% \\
\mathrm{C} 4 \quad & =100(0,37) \%=37 \\
\mathrm{C} 5 & =100\left(\frac{(86-75)}{(86-70)} \%\right. \\
\mathrm{C} 6 & =100 \frac{(86-70)}{(86-70)} \% \\
& =100(1)=100 \\
\mathrm{C} 7 & =100 \frac{(86-86)}{(86-70)} \% \\
& =100(0) \frac{(86-70)}{(86-70)} \% \\
& =100(1) \%=100
\end{aligned}
$$

Pengumpulan Data Kuisioner

$$
\begin{array}{ll}
\mathrm{C} 1 & =100 \frac{(80-70)}{(80-70)} \% \\
& =100(1) \%=100 \\
\mathrm{C} 2 & =100 \frac{(80-75)}{(80-70)} \% \\
\mathrm{C} 3 & =100(0,5) \%=50 \\
\mathrm{C} 4 & =100 \frac{(80-75)}{(80-70)} \% \\
\mathrm{C} 5 & =100 \frac{(0,5) \%=50}{(80-70)} \% \\
\mathrm{C} 6 & =100 \frac{(1) \%=100}{(80-70)} \% \\
\mathrm{C} 7 & =100 \frac{(0) \%=0}{(80-70)} \% \\
& =100(1) \%=100 \\
& =100 \frac{(80-80)}{(80-70)} \% \\
& =100(0) \%=0
\end{array}
$$

Observasi Sampel

$$
\begin{aligned}
\mathrm{C} 1 & =100 \frac{(86-80)}{(86-70)} \% \\
\mathrm{C} 2 & =100(0,37) \%=37 \\
& =100 \frac{(86-86)}{(86-70)} \% \\
\mathrm{C} 3 & =100(0) \%=0 \\
\mathrm{C} 4 & =100 \frac{(86-80)}{(86-70)} \% \\
\mathrm{C} 5 & =100 \frac{(0,37) \%=37}{(86-75)} \% \\
\mathrm{C} 6 & =100 \frac{(0,68) \%}{(86-70)} \% 68 \\
\mathrm{C} & =100(1) \%=100 \frac{(86-80)}{(86-70)} \%
\end{aligned}
$$




$$
\begin{aligned}
& =100(0.37) \%=37 \\
& \mathrm{C} 7 \quad=100 \frac{(86-86)}{(86-70)} \% \\
& =100(0) \%=0
\end{aligned}
$$

Tata Bahasa

\begin{tabular}{|c|c|c|c|c|}
\hline \multirow[b]{2}{*}{$\begin{array}{c}\text { Nama Team } \\
\text { Survei }\end{array}$} & \multicolumn{4}{|c|}{ Faktor } \\
\hline & $\begin{array}{c}\text { Manajemen } \\
\text { Strategis }\end{array}$ & $\begin{array}{c}\text { Pengumpulan Data } \\
\text { Kuisioner }\end{array}$ & $\begin{array}{c}\text { Observasi } \\
\text { Sampel }\end{array}$ & Tata Bahasa \\
\hline $\begin{array}{l}\text { Team Survei } \\
\text { Kesehatan }\end{array}$ & 68 & 100 & 37 & 0 \\
\hline $\begin{array}{l}\text { Team Survei } \\
\text { Pendidikan }\end{array}$ & 100 & 50 & 0 & 0 \\
\hline $\begin{array}{l}\text { Team Survei } \\
\text { Ekonomi } \\
\text { Team Survei }\end{array}$ & 37 & 50 & 37 & 100 \\
\hline $\begin{array}{l}\text { Hubungan } \\
\text { Masyarakat }\end{array}$ & 68 & 100 & 68 & 100 \\
\hline $\begin{array}{l}\text { Team Survei } \\
\text { Lingkungan } \\
\text { Team Survei }\end{array}$ & 100 & 0 & 100 & 100 \\
\hline $\begin{array}{l}\text { Penberdayaan } \\
\text { Wanita }\end{array}$ & 0 & 100 & 37 & 0 \\
\hline $\begin{array}{l}\text { Team Survei } \\
\text { Pembudidayaan }\end{array}$ & 100 & 0 & 0 & 100 \\
\hline Jumlah & 473 & 400 & 279 & 400 \\
\hline
\end{tabular}

$$
\begin{array}{ll}
\mathrm{C} 1 & =100 \frac{(75-75)}{(75-70)} \% \\
& =100(0) \%=0 \\
\mathrm{C} 2 & =100 \frac{(75-75)}{(75-70)} \% \\
\mathrm{C} 3 & =100(0) \%=0 \\
\mathrm{C} 4 & =100 \frac{(75-70)}{(75-70)} \% \\
\mathrm{C} 5 & =100 \frac{(1) \%=100}{(75-70)} \% \\
& =100(1) \%=100 \\
\mathrm{C} 6 & =100(75-70) \\
& =100 \frac{(75-70)}{(75-75)} \% \\
\mathrm{C} 7 & =100(0) \%=0 \\
& =100 \frac{(75-70)}{(75-70)} \% \\
& =100(1) \%=100
\end{array}
$$

Tabel 6. Nilai Utility Kriteria

5. Menghitung nilai akhir masing-masing.

$$
\begin{aligned}
\text { Manajemen Strategis } & =68 \times(0,2) \\
& =13,6 \\
\text { C2 } 1 & =100 \times(0.2) \\
& =20 \\
\text { C3 } & =37 \times(0.2) \\
& =7,4 \\
\text { C4 } & =68 \times(0.2) \\
& =13,6 \\
\text { C5 } & =100 \times(0,2) \\
& =20 \\
\text { C6 } & =0 \times(0.2) \\
& =0 \\
\text { C7 } & =100 \times(0.2) \\
& =20 \\
\text { C1 } & =100 \times(0,2)
\end{aligned}
$$


Observasi Sampel

$$
\begin{aligned}
& \begin{aligned}
& =20 \\
\mathrm{C} 2 & =50 \times(0.2)
\end{aligned} \\
& =10 \\
& \mathrm{C} 3=50 \times(0.2) \\
& =10 \\
& \mathrm{C} 4=100 \times(0.2) \\
& =20 \\
& \text { C5 }=0 \times(0,2) \\
& =0 \\
& \text { C6 }=100 \times(0.2) \\
& =20 \\
& \text { C7 }=0 \times(0.2) \\
& =0 \\
& \mathrm{C} 1=37 \times(0,4) \\
& =14,8 \\
& \mathrm{C} 2=0 \times(0.4) \\
& =0 \\
& \text { C3 }=37 \times(0.4) \\
& =14,8 \\
& \mathrm{C} 4=68 \times(0.4) \\
& =27,2 \\
& \text { C5 }=100 \times(0,4) \\
& =40 \\
& \text { C6 }=37 \times(0.4) \\
& =14,8 \\
& \text { C7 }=0 \times(0.4) \\
& =0 \\
& \mathrm{C} 1=0 \times(0,2) \\
& =0 \\
& \mathrm{C} 2=0 \times(0.2) \\
& =0 \\
& \text { C3 }=100 \times(0.2) \\
& =20 \\
& \mathrm{C} 4=100 \times(0.2) \\
& =20 \\
& \mathrm{C} 5=100 \times(0,2) \\
& =20 \\
& \text { C6 }=0 \times(0.2) \\
& =0 \\
& \text { C7 }=100 \times(0.2) \\
& =20
\end{aligned}
$$

Tabel 7. Evaluasi Faktor Team survei Kesehatan

\begin{tabular}{lccc}
\hline \multicolumn{1}{c}{ Faktor } & Nilai Utility & Wj(Bobot) & Nilai akhir \\
\hline Manajemen Strategis & 13,6 & 0,2 & 2,72 \\
Pengumpulan Data Kuisioner & 20 & 0,2 & 4 \\
Observasi Sampel & 14,8 & 0,4 & 5,92 \\
Tata Bahasa & 0 & 0,2 & 0 \\
& & & 12,64 \\
\hline
\end{tabular}

Tabel 8. Evaluasi Faktor Team Survei Pendidikan

\begin{tabular}{lccc}
\hline \multicolumn{1}{c}{ Faktor } & Nilai Utility & Wj(Bobot) & Nilai akhir \\
\hline Manajemen Strategis & 20 & 0,2 & 4 \\
Pengumpulan Data Kuisioner & 10 & 0,2 & 2 \\
Observasi Sampel & 0 & 0,4 & 0 \\
Tata Bahasa & 0 & 0,2 & 0 \\
& & & 6 \\
\hline
\end{tabular}

Tabel 9. Evaluasi Faktor Team Survei Ekonomi 


\begin{tabular}{lccc}
\hline Manajemen Strategis & 7,4 & 0,2 & 1,48 \\
Pengumpulan Data Kuisioner & 10 & 0,2 & 2 \\
Observasi Sampel & 14,8 & 0,4 & 5,92 \\
Tata Bahasa & 20 & 0,2 & 4 \\
& & & 13,4 \\
\hline
\end{tabular}

Tabel 10. Evaluasi Faktor Team Survei Hubungan Masyarakat

\begin{tabular}{lccc}
\hline \multicolumn{1}{c}{ Faktor } & Nilai Utility & Wj (Bobot) & Nilai Akhir \\
\hline Manajemen Strategis & 13,6 & 0,2 & 2,72 \\
Pengumpulan Data Kuisioner & 20 & 0,2 & 4 \\
Observasi Sampel & 27,2 & 0,4 & 10,88 \\
Tata Bahasa & 20 & 0,2 & 4 \\
& & & 21,6 \\
\hline
\end{tabular}

Tabel 11. Evaluasi Faktor Team Survei Lingkungan

\begin{tabular}{lccc}
\hline \multicolumn{1}{c}{ Faktor } & Nilai Utility & Wj(Bobot) & Nilai akhir \\
\hline Manajemen Strategis & 20 & 0,2 & 4 \\
Pengumpulan Data Kuisioner & 0 & 0,2 & 0 \\
Observasi Sampel & 40 & 0,4 & 16 \\
Tata Bahasa & 20 & 0,2 & 4 \\
& & & 24 \\
\hline
\end{tabular}

Tabel 12. Evaluasi Faktor Team Survei Pemberdayaan Wanita

\begin{tabular}{lccc}
\hline \multicolumn{1}{c}{ Faktor } & Nilai Utility & Wj(Bobot) & Nilai akhir \\
\hline Manajemen Strategis & 0 & 0,2 & 0 \\
Pengumpulan Data Kuisioner & 20 & 0,2 & 4 \\
Observasi Sampel & 14,8 & 0,4 & 5,92 \\
Tata Bahasa & 0 & 0,2 & 0 \\
& & & 9.92 \\
\hline
\end{tabular}

Tabel 13. Evaluasi Faktor Team Survei Pembudidayaan

\begin{tabular}{lccc}
\hline \multicolumn{1}{c}{ Faktor } & Nilai Utility & Wj(Bobot) & Nilai akhir \\
\hline Manajemen Strategis & 20 & 0,2 & 4 \\
Pengumpulan Data Kuisioner & 0 & 0,2 & 0 \\
Observasi Sampel & 0 & 0,4 & 0 \\
Tata Bahasa & 20 & 0,2 & 4 \\
& & & 8 \\
\hline
\end{tabular}

Tabel 14. Hasil Evaluasi Faktor Keseluruhan Team Survei

\begin{tabular}{lc}
\hline \multicolumn{1}{c}{ Nama Team Survei } & Nilai Akhir \\
\hline Team Survei Kesehatan & 12,64 \\
Team Survei Pendidikan & 6 \\
Team Survei Ekonomi & 13,4 \\
Team Survei Hubungan Masyarakat & 21,6 \\
Team Survei Lingkungan & 24 \\
Team Survei Pemberdayaan Wanita & 9,92 \\
Team Survei Pembudidayaan & 8 \\
\hline
\end{tabular}

\section{KESIMPULAN}

Dari hasil penelitian yang penulis lakukan pada SNI (Serikat Nelayan Indonesia), maka penulis mengambil kesimpulan penerapan kriteria pada team survei terbaik dapat memberikan hasil yang objektif pada pihak SNI (Serikat Nelayan Indonesia) dan memuhadahkan SNI untuk mendapatkan team survei terbaik sesuai dengan kriteria. Penerapan metode SMART pada pemilihan team survei terbaik hasil yang di dapatkan jauh lebih mudah dari metode-metode sistem pendukung keputusan lainnya.

\section{REFERENCES}

[1] S. Kusumadewi, S. Hartati, A. Harjoko, and Retantyo Wardoyo, Fuzzy Multi-Attribute Decision Making (FUZZY MADM). 2006.

[2] D. Nofriansyah, Konsep Data Mining Vs Sistem Pendukung Keputusan. 2015. 
[3] D. Nofriansyah, Multi Criteria Decision Making. Yogyakarta: Deepublish, 2017.

[4] T. Limbong et al., Sistem Pendukung Keputusan: Metode \& Implementasi. Medan: Yayasan Kita Menulis, 2020.

[5] Efraim Turban and Jay E. Aronson, Decision Support System and Intelligent Systems. 2001.

[6] Risawandi and R. Rahim, "Study of the Simple Multi-Attribute Rating Technique For Decision Support," IJSRST, vol. 2, no. 6, pp. 491-494, 2016.

[7] A. Priyolistiyanto, "Implementasi Metode Simple Multi Attribute Rating Technique Exploiting Rank (SMARTER) pada Sistem Pendukung Keputusan Sanksi Pelanggaran Tata Tertib Sekolah,” Pros. Semin. Nas. Ilmu Komput., 2013.

[8] M. Safrizal, "Sistem Pendukung Keputusan Pemilihan Karyawan Teladan dengan Metode SMART (Simple Multi Attribute Rating Technique)," 2015. 